Jerry P. Nolan

Jasmeet Soar

Alain Cariou

Tobias Cronberg

Véronique R. M. Moulaert

Charles D. Deakin

Bernd W. Bottiger

Hans Friberg

Kjetil Sunde

Claudio Sandroni

\section{Erratum to: European Resuscitation Council and European Society of Intensive Care Medicine 2015 guidelines for post- resuscitation care}

Published online: 9 December 2015

(C) Springer-Verlag Berlin Heidelberg and ESICM 2015

The online version of the original article can be found under doi:10.1007/s00134-015-4051-3.

\section{J. P. Nolan (ه)}

Department of Anaesthesia and Intensive Care Medicine, Royal United Hospital, Bath, UK

e-mail: jerry.nolan@nhs.net

\section{J. P. Nolan}

School of Clinical Sciences, University of Bristol, Bristol, UK

J. Soar

Anaesthesia and Intensive Care Medicine, Southmead Hospital, Bristol, UK

\author{
A. Cariou \\ Cochin University Hospital (APHP) and Paris Descartes University, \\ Paris, France
}

T. Cronberg

Division of Neurology, Department of Clinical Sciences, Lund

University, Lund, Sweden

\section{R. M. Moulaert}

Adelante, Centre of Expertise in Rehabilitation and Audiology, Hoensbroek, The Netherlands

\section{D. Deakin}

Cardiac Anaesthesia and Cardiac Intensive Care and NIHR Southampton Respiratory Biomedical Research Unit, University Hospital, Southampton, UK

\section{B. W. Bottiger}

Department of Anaesthesiology and Intensive Care Medicine, University Hospital of Cologne, Cologne, Germany

H. Friberg

Division of Anesthesia and Intensive Care Medicine, Department of Clinical Sciences, Lund University, Lund, Sweden

\section{K. Sunde}

Division of Emergencies and Critical Care, Department of Anaesthesiology, Oslo University Hospital and Institute of Clinical Medicine, University of Oslo, Oslo, Norway

C. Sandroni

Department of Anaesthesiology and Intensive Care, Catholic

University School of Medicine, Rome, Italy

\section{Erratum to: Intensive Care Med (2015) \\ 41:2039-2056 \\ DOI 10.1007/s00134-015-4051-3}

A mistake was made in Fig. 2: in the lower blue box on the right-hand side, poor outcome is reported as being "very likely", whereas in fact it is "likely". The corrected Fig. 2 is supplied here. The authors regret this error and apologize for any inconvenience. 


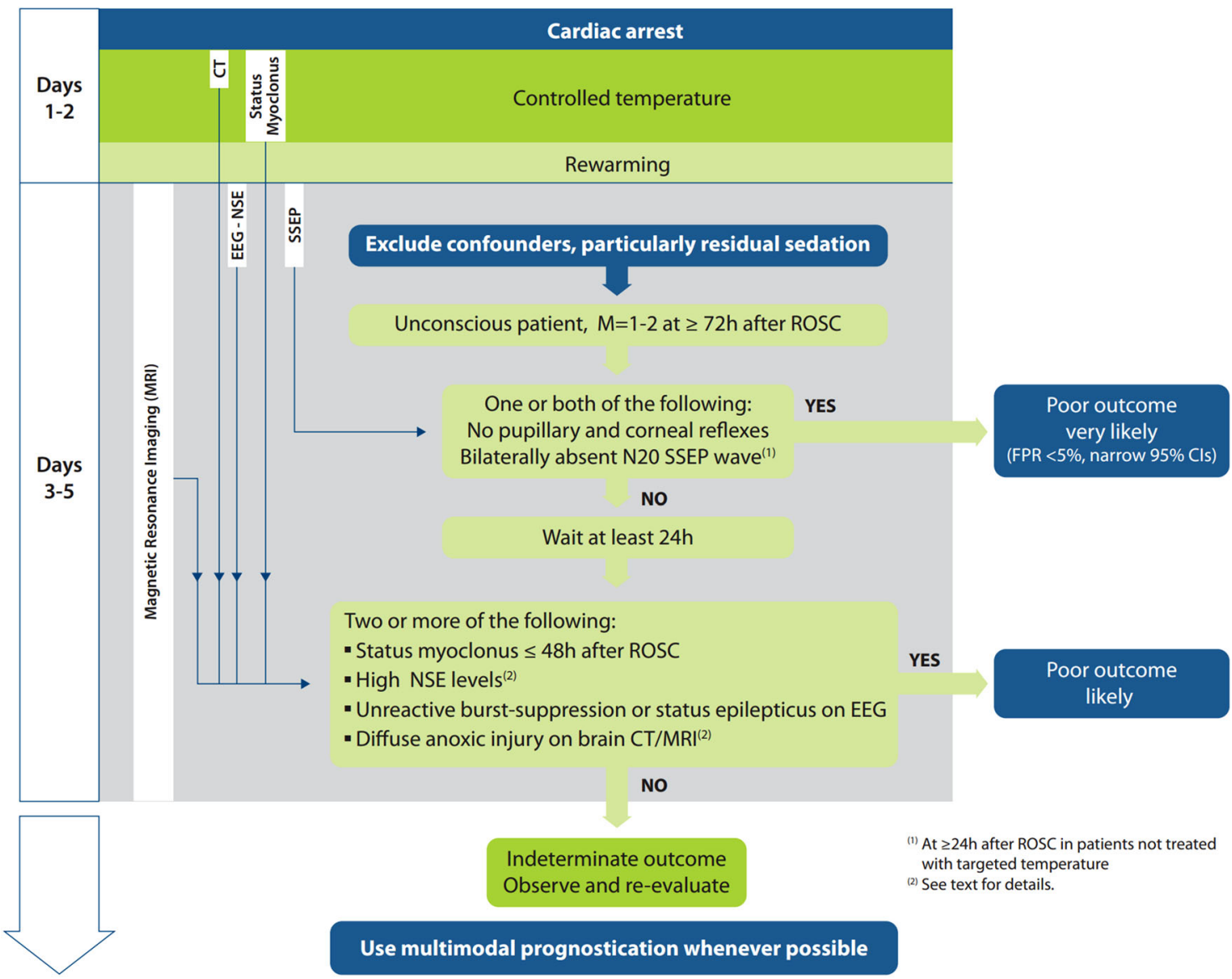

Fig. 2 Prognostication strategy algorithm. EEG electroencephalography, NSE neuron specific enolase, SSEP somatosensory evoked potentials, ROSC return of spontaneous circulation, FPR false positive rate, $C I$ confidence interval 